\title{
Efektivitas pemasaran dari mulut ke mulut pengguna Paviliun Padjadjaran Rumah Sakit Gigi dan Mulut

\author{
Yandi Kusmulyandi ${ }^{{ }^{*}}$, Cucu Zubaedah ${ }^{1}$, Kosterman ${ }^{2}$
}

${ }^{1}$ Departemen Kesehatan Gigi Masyarakat Fakultas Kedokteran Gigi Universitas Padjadjaran

${ }^{1}$ Departemen Ilmu Teknologi dan Material Fakultas Kedokteran Gigi Universitas Padjadjaran

*Korespondensi : yandikusmulyandi250496@gmail.com

\begin{abstract}
ABSTRAK
Pendahuluan: Efektivitas Pemasaran merupakan hal yang penting dalam keberhasilan pelaksanaan jasa pemasaran khususnya pelayanan kesehatan gigi dan mulut. Tujuan dari penelitian ini adalah untuk mengetahui Efetivitas Pemasaran dari Mulut ke Mulut Pengguna di Paviliun Padjadjaran Rumah Sakit Gigi dan Mulut Universitas Padjadjaran. Metode: metode dalam penelitian ini adalah survey dengan jenis penelitin deskriptif. Pengambilan sampel dengan cara consecutive sampling. Penelitian dilakukan di Paviliun Padjadjaran Rumah Sakit Gigi dan Mulut Universitas Padjadjaran dengan menggunakan kuisioner. Hasil: sebanyak 84 orang sampel menunjukan bahwa secara keseluruhan rata-rata efektivitas pemasaran pengguna Paviliun PadjadjaranRumah Sakit Gigi dan Mulut Universitas Padjadjaran sebesar 67,5\%.Nilai tersebut termasuk kedalam kategori cukup efektif. Simpulan: Tingkat efektivitas pemasaran darimulut ke mulutdi bagian Paviliun Padjadjaran RSGM Unpad dalam hal ini meliputi pasien yang loyal, keluarga pasien, dan penunggu terhadap pelayanan yang diberikan di Paviliun Padjadjaran RSGM Unpad dinilai cukup efektif dengan persentase sebesar 67,5\%.
\end{abstract}

Kata kunci: Pemasaran mulut ke mulut, Pengguna, paviliun Padjadjaran

\section{Marketing effectiveness from word of mouth to users of the pavilion Dental Padjadjaran and Oral Hospital,}

\section{ABSTRACT}

Introduction: Marketing effectiveness is an important thing in the successful implementation of dental and oral health services. The purpose of this study is to determine the Effectiveness of 'Word of Mouth Marketing' from the customers at Padjadjaran Pavilion of Padjadjaran University. Methods: The method used in this study was survey method with descriptive. Sampling by 'consecutive sampling'. The location of the study was conducted at Paviliun Padjadjaran of Padjadjaran University'sDentalandOralHospitalandwasconductedbydirectobservationusingquestions. Results: The results of this research from 84 samples showed that overall average of marketing effectiveness in Padjadjaran Pavilion users amounted to 67.5\%. The Value goes into the effectiveness enough category. Conclusion: The level of marketing effectiveness from word of mouth at the Padjadjaran Pavilion in RSGM Unpad in this case includes loyal patients, patient families, and caregivers for the services provided at Padjadjaran Pavilion RSGM Unpad considered to be quite effective with a percentage of $67.5 \%$

Keywords: Marketing word of mouth, Customers, Padjadjaran pavilion 


\section{PENDAHULUAN}

Kesehatan merupakan aspek yang sangat penting dalam kehidupan manusia, terbukti berbagai cara dilakukan orang untuk mendapatkan taraf kesehatan yang prima. Apabila seseorang menderita sakit biasanya mereka akan segera berusaha untuk mengatasi dan mengobati gangguannya atau penyakitnya hingga sembuh (Ikawati, 2001). Dalam mencapai kesembuhan yang diharapkan seseorang memerlukan bantuan dari pihak lain yaitu sarana pelayanan kesehatan rumah sakit, sebagai institusi yang berwenang memberikan pelayanan kesehatan kepada masyarakatluas.

Rumah sakit merupakan tempat pelayanan kesehatan bagi masyarakat. Undang- undang Republik Indonesia No.44 Tahun 2009, menyatakan bahwa rumah sakit adalah institusi pelayanan kesehatan yang menyelenggarakan pelayanan kesehatan perorangan secara paripurna yang menyediakan pelayanan rawat inap, rawatjalan, dangawat darurat.

Kesadaran masyarakat yang semakin tinggi terhadap pentingnya kesehatan merupakan salah satu alasan bahwa kebutuhan akan prasarana kesehatan juga semakin meningkat. Selain itu, masyarakat akan semakin pandai untuk memilih jasa pelayanan kesehatan manakah yang terbaik dan sesuai dengan apa yang mereka inginkan dan butuhkan (Burns and Neiser, 2006). Kesadaran akan kesehatan yang semakin tinggi, tentunya masyarakat akan menggunakan jasa pelayanan kesehatan yang terbaik. Menentukan jasa pelayanan yang terbaik, masyarakat biasanya mendapat informasi dari orang lain (Weiss, 2011).

Word of mouth atau informasi dari mulut ke mulut adalah komunikasi dari orang ke orang antara sumber pesan dan penerima pesan dimana penerima pesan menerima pesan dengan cara tidak komersil mengenai suatu produk, pelayanan, atau merek. Word of mouth menjadi referensi yang membentuk harapan pelanggan, karena mereka langsung mendapatkan informasi dari orang yang telah menggunakan jasa

Tabel 1 Distribusi Frekuensi-Kuantitatif.

\begin{tabular}{ccc}
\hline Efektivitas & Frekeunsi & Persen \\
\hline Efektif & 11 & $13.1 \%$ \\
Cukup Efektif & 63 & $75.0 \%$ \\
Sangat Efektif & 10 & $11.9 \%$ \\
\hline Total & $\mathbf{8 4}$ & $\mathbf{1 0 0 . 0} \%$ \\
\hline
\end{tabular}

tersebut mengenai baik atau buruknya suatu jasa tersebut. Word of mouth merupakan rekomendasi dan komentar pelanggan sekitar pengalaman mereka atas layanan jasa dan produk yang betul - betul mempengaruhi keputusan pelanggan atau perilaku pembelian mereka. Word of mouth dapat membentuk kepercayaan para pelanggan (Weiss, 2011). Tujuan dari penelitian ini adalah untuk mengetahui Efetivitas Pemasaran dari Mulut ke Mulut Pengguna di Paviliun Padjadjaran Rumah Sakit Gigi dan Mulut Universitas Padjadjaran.

\section{METODE}

Jenis penelitian yang digunakan dalam penelitian ini adalah penelitian deskriptif yang bersifat survey,penelitian dilakukan di Rumah Sakit Gigi dan Mulut Unpad pada bulan Desember tahun 2017Januari 2018,cara analisis datanya menggunakan tekhnik survey,analisis data dilakukan dengan analisis data distribusifrekuensi relatif.

Efektivitas pemasaran dari mulut ke mulut di Paviliun Padjadjaran RSGM Unpad, menggunakan pengamatan secaralangsung. Pengamatanlangsung adalah aktivitas mengumpulkan data atau keterangan yang didapat dengan melakukan usaha-usaha pengamatan secara langsung ke tempat yang ditinjau serta peneliti mendampingi responden pada saat responden sedang mengisi kuisioner.

\section{HASIL}

Hasil penelitian sebagai berikut:

Tabel 1 menunjukan bahwa efektivitas pemasaran dari mulut ke mulut di Paviliun Padjadjaran RSGM Unpad berdasarkan distribusi frekuensi sebanyak delapan puluh empat orang terbilang cukupefektif.

Tabel 2 menunjukan bahwa efektivitas pemasaran dari mulut ke mulut di Paviliun Padjadjaran RSGM Unpad berdasarkan Quantitative Male Patient sebanyak tiga puluh dua orang terbilang cukupefektif.

Tabel 2 Distribusi Frekuensi-laki-laki.

\begin{tabular}{ccc}
\hline Efektivitas & Frekuensi & Persen \\
\hline Efektif & 4 & $12.5 \%$ \\
Cukup Efektif & 26 & $81.3 \%$ \\
Sangat Efektif & 2 & $6.3 \%$ \\
\hline Total & $\mathbf{3 2}$ & $\mathbf{1 0 0 . 0} \%$ \\
\hline
\end{tabular}


Tabel 3 Distribusi Frekuensi-perempuan.

\begin{tabular}{ccc}
\hline Efektivitas & Frekuensi & Persen \\
\hline Efektif & 7 & $13.5 \%$ \\
Cukup Efektif & 37 & $71.2 \%$ \\
Sangat Efektif & 8 & $15.4 \%$ \\
\hline Total & $\mathbf{5 2}$ & $\mathbf{1 0 0 . 0 \%}$ \\
\hline
\end{tabular}

Tabel 4. Distribusi Frekuensi per-item

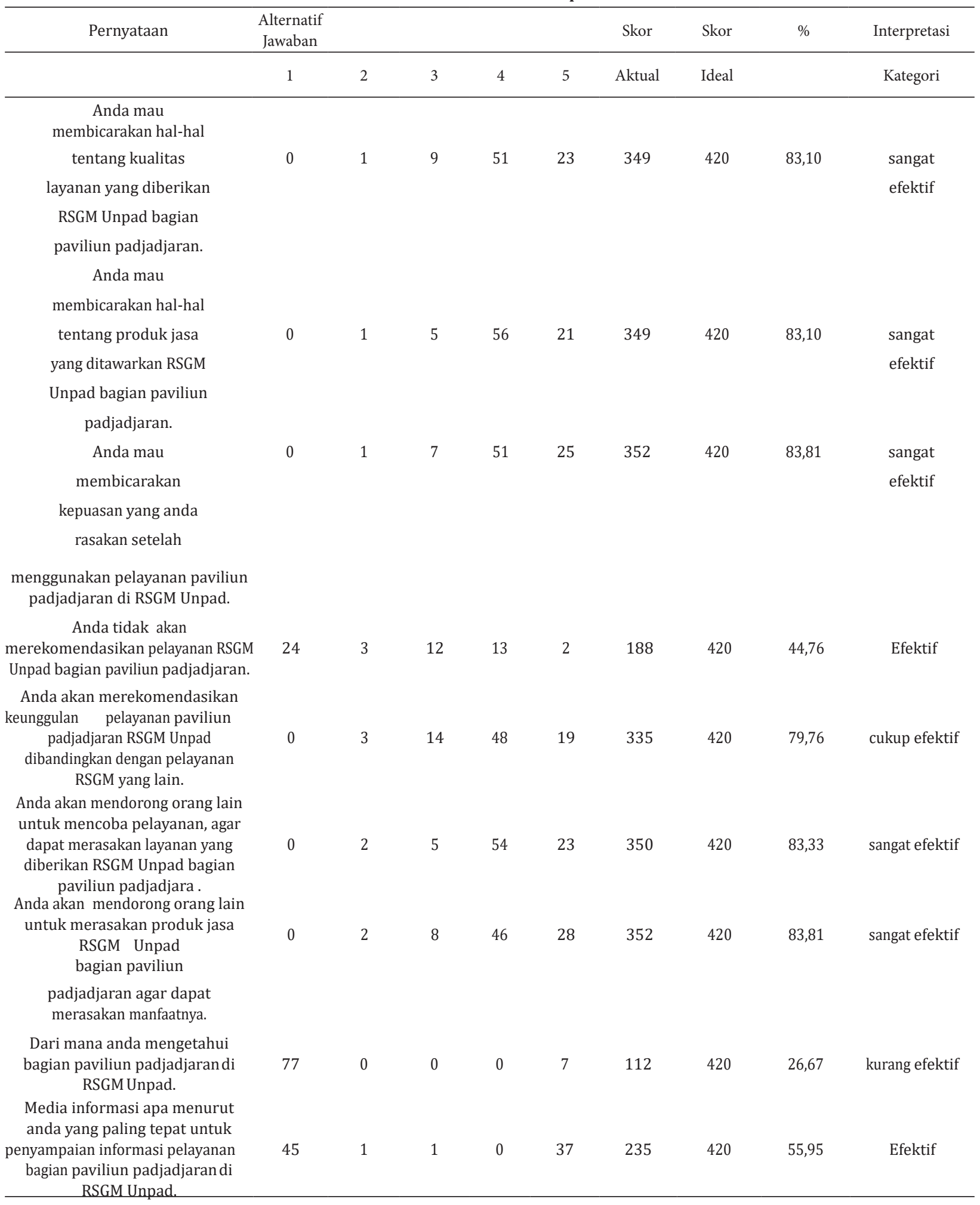




\section{PEMBAHASAN}

Dimensi efektivitas pemasaran adalah membicarakan, merekomendasikan dan mendorong. Nilai dimensi membicarakan pada penelitian ini menunjukan kategori sangatefektif. Dimensi membicarakan pada penelitian ini memiliki tiga item pertanyaan. Item pertama tentang bagaimana responden mau membicarakan hal-hal kualitas layanan yang diberikan bagian Paviliun Padjadjaran RSGM Unpad termasuk kedalam kategori sangat efektif. Pendapat responden mengenai item pertama, disebabkan pelayanan yang diberikan di bagian Paviliun Padjadjaran dianggap tepat dan efektif dalam mengatasi keluhan yang dialami pengguna. Tepat didalam menentukan diagnosis dan menentukan terapi. Apabila pengguna puas mengenai pelayanan di Paviliun Padjadjaran, pengguna akan membicarakan kepada orang lain mengenai pelayanan di Paviliun Padjadjaran

RSGMUnpaddantentunya akanberdampakbaik kepada RSGM sebagai institusi. Dampak baik tersebut salah satunya dengan meningkatnya pendapatan RSGM Unpad khususnya di bagian Paviliun Padjadjaran dan pasien menjadi bertambah. Dampak tersebut akan berpengaruh kepada reputasi institusi serta akan berpengaruh positif terhadap respon pengguna jasa. Hal ini sejalan dengan penelitian yang dilakukan oleh Azwar Azrul (1996) dimana pelayanan kesehatan yang disediakan harus dapat memuaskan pengguna jasa pelayanan dan diselenggarakan berdasarkan standar yang ditetapkan (Azwar, 1996) .

Item kedua tentang bagaimana responden mau membicarakan hal-hal tentang produk jasa yang ditawarkan RSGM Unpad bagian Paviliun Padjadjaran termasuk kedalam kategori sangat efektif. Pendapat responden mengenai item kedua disebabkan produk jasa yang ditawarkan Paviliun Padjadjaran sangat memuaskan. Dilihat dari hasil jasa yang ditawarkan pada proses penyembuhan, dokter menjelaskan kepada pengguna mengenai hal-hal apa saja yang tidak boleh dilakukan setelah dilakukannya tindakan dan kualitas jasa yang diberikan sangat baik. Produk jasa yang ditawarkan dikerjakan oleh dokter yang ahli dibidangnya sehingga menghasilkan kualitas jasa yang baik. Hal ini sejalan dengan penelitian Brown et al (2005) bahwa konsumen berbicara kepada orang lain mengenai pendapatnya tentang suatu merek, produk, layanan dari perusahaan tertentu ketika konsumen merasa terpuaskan dengan merek, produk, layanan darisuatuperusahaan(Brown,2005).

Item ketiga tentang bagaimana responden mau membicarakan kepuasan yang dirasakan setelah menggunakan pelayanan Paviliun Padjadjaran RSGM Unpad termasuk kedalam kategori sangat efektif. Hasil penelitian menunjukkan kepuasan dapat dilihat dari sikap dokter yang ramah, pelayanan yang baik, penerimaan pasien di Paviliun Padjadjaran yang tidak berbelit-belit, dan kualitas pelayanan yang diberikan sangat baik. Responden memperkuat dengan pendapat bahwa sikap dokter yang bertugas sangat ramah pada pengguna, pelayanan yang diberikan oleh dokter maksimal dan responden memberikan penilaian item pada kuisioner dengan kategori sangat efekif. Hal ini sejalan dengan penelitian Babin Barry (2005), dimana seseorang akan membicarakan ha-hal positif tentang suatu produk kepada orang lain pada saat konsumen mendapatkan kepuasan yang maksimal dan memiliki bahan menarik untuk dibicarakan dengan orang lain (Babin, 2005).

Hasil penelitian secara keseluruhan mengenai dimensi membicarakan termasuk sangat efektif karena ketiga item pertanyaan setelah dilakukan penelitian termasuk kategori sangat efektif, serta tidak ada item pertanyaan pada dimensi membicarakan yang termasuk kategori kurang efektif. Nilai dimensi merekomendasikan pada penelitian ini menunjukan kategori cukup efektif. Dimensi merekomendasikan pada penelitian ini memiliki dua item pertanyaan. Item pertama mengenai bagaimana responden akan merekomedasikan pelayanan RSGM Unpad bagian Pavilun Padjadjaran termasuk kedalam kategori efektif Kategori efektif karena responden merasa terpuaskan dengan pelayanan di Paviliun padjadjaran, tetapi responden merasa perlu adanya pembaruan sistem dari sistem manual pada sistem yang lebih maju seperti pemanggilan pasien secara otomatis tanpa harus dilakukan oleh petugas. Pelayanan petugas yang diberikan kepada pasien sangat baik, dapat dilihat dari penjadwalan pasien yang sudah teratur sehari sebelum dilakukan tindakan pelayanan dan peneliti setuju dengan pendapat pasien mengenai perlu adanya pembaruansystem.

Item kedua mengenai bagaimana responden akan merekomendasikan keunggulan pelayanan paviliun padjadjaran RSGM Unpad dibandingkan dengan pelayanan RSGM yang lain termasuk kedalam kategori cukup efektif. Peneliti berpendapat Paviliun Padjadjaran memiliki suatu keunggulan yaitu dilihat dari dokter yang bekerja, dokter spesialis. Responden memperkuat dengan pendapat bahwa Paviliun Padjadjaran memiliki keunggulan lain seperti 
ruangan yang khusus dan tindakan yang khusus dibandingkan dengan pasien dibagian regular. Dengan keunggulan tersebut menjadi suatu hal yang membuat responden akan merekomendasikan bagian Paviliun Padjadjaran kepada orang lain. Hal ini sejalan dengan penelitian Babin Barry (2005) bahwa konsumen menginginkan produk yang bisa memuaskan dan memiliki keunggulan dibandingkan dengan yang lain, sehingga bisa direkomendasikan kepada orang lain (Babin, 2005).

Hasil penelitian secara keseluruhan mengenai dimensi merekomendasikan termasuk cukup efektif. Setelah dilakukan penelitian pada dimensi merekomendasikan item pertanyaan kedua cukup efektif dibandingkan pertanyaan item pertama. Nilai dimensi mendorong pada penelitian ini menunjukan kategori sangat efektif. Dimensi merekomendasikan pada penelitian ini memiliki dua item pertanyaan. Item pertama mengenai bagaimana responden akan mendorong orang lain untuk merasakan produk jasa RSGM Unpad bagian Paviliun Padjadjaran agar dapat merasakan manfaatnya.

Hasil penelitian item pertama termasuk kategori sangat efektif. Item kedua mengenai bagaimana responden akan mendorong orang lain untuk mencoba pelayanan agar dapat merasakan layanan yang diberikan RSGM Unpad bagian Paviliun Padjadjaran. Setelah dilakukan penelitian, item kedua termasuk kedalam kategori sangat efektif. Hal ini sejalan dengan penelitian Babin Barry (2005) bahwa konsumen menginginkan timbal balik yang sesuai pada saat mempengaruhi orang lain untuk memakai produk ataujasayang akan diberitahukan (Babin, 2005).

Kedua item pertanyaan tersebut termasuk sangat efektif, dapat dilihat dari pendapat responden yang mengalami dan mengamati prosedur penerimaan yang dianggap sesuai dengan harapan pengguna mengenai prosedur penerimaan yang tidak terlalu rumit, berbelitbelit, dan sederhana. Karena pasien datang dengan keluhan yang sedang di rasakan dan berharap langsung ditangani dan tidak memerlukan prosedur yang berbelit-belit.

Kemudahan prosedural di Paviliun Padjadjaran, akan mempengaruhi persepsi pasien terhadap pelayanan jasa yang diberikan. Pengguna yang merasakan langsung kemudahan prosedur penerimaan yang cepat dan sederhana akan menyebabkan pengguna cenderung akan mendorong orang lain untuk merasakan pelayanan di Paviliun Padjadjaran . Hal ini sejalan dengan penelitian yang dilakukan Kolter dan Keller (2009) bahwa pemasaran mencakup keseluruhan sistem kegiatan mulai dari prosedural, penentuan harga, jasa dan pendistribusian barang (Kolter, 2009). Setelah dilakukan pembahasan mengenai semua item per dimensi daripenelitian yang dilakukan didapatkan hasil bahwa item yang termasuk kategori sangat efektif adalah item nomor satu,dua, dan tiga pada dimensimembicarakan sertaitem nomor satu,dua pada dimensi mendorong. Pada item nomor satu dimensi merekomendasikan termasuk kedalam kategori efektif dan item nomor dua pada dimensi merekomendasikan termasuk kedalam kategori cukup efektif. Hasil dari penelitian yang telah dilakukan terhadap pengguna di Paviliun Padjadjaran RSGM Unpad menunjukan bahwa gambaran efektivitas pemasaran dari mulut ke mulut adalah cukup efektif dengan presentase skor empat.

\section{SIMPULAN}

Tingkat efektivitas pemasaran dari mulut ke mulut di bagian Paviliun Padjadjaran RSGM Unpad dalam hal ini meliputi pasien yang loyal, keluarga pasien, dan penunggu terhadap pelayanan yang diberikan di Paviliun Padjadjaran RSGM Unpad dinilai cukup efektif dengan persentase sebesar $67,5 \%$.

\section{DAFTAR PUSTAKA}

1. Azwar, A. 1996. Menjaga Mutu Pelayanan Kesehatan Aplikasi Prinsip Lingkaran Pemecahan Masalah, Jakarta: Pustaka Sinar Harapan. Pp 64-65.

2. Aditama, YT. 2002. Rumah sakit dan konsumen, Jakarta : PPFKM UI. Pp 7-21.

3. Babin, Barry J. 2005. Modelling Consumer Statisfaction and Word of Mouth: Restoran Patronage in Korea. The Journal of Services. Pp 3438.

4. Brown, et al. 2005. Spreading The Words : Investigating Antecedents of Customer's Positive Word ofMouthIntention And Behavior in Retailing Context, Academy ofMarketing Science Journals, Vol.33, no 2.Pp 123-138.

5. Burns, D.and Neiser,L.2006.CustomerSatisfaction in aRetailSetting: Contribution of Emotion, International Journal of Retail \& Distribution Managment,34(1).Pp49-56.

6. Fandy Tjiptono. 2006 . Manajemen Pemasaran. Edisi pertama. Yogyakarta: Andi.P 5. Gellynck, P.X. 2009.Introduction to Business Management.Jakarta 
:RinekaCipta.Pp10-1.

7. Hardjam, R. 2001. Efektivitas pelayanan kesehatan di rumah sakit umum kabupaten polman sulawesi barat.

8. Hasan. 2002. Pengaruh Kualitas Pelayanan terhadap Kepuasan Pelanggan Serta Dampaknyaterhadap Word of Mouth (WOM), pada Koperasi Simpan Pinjam (KSP) Usaha Mandiri, Kota Bekasi, Jawa Barat.Jakarta:Ghalia Indonesia.Pp33-50.

9. Hasan. 2002 . Word of Mouth Marketing Sebagai bauran Komunikasi Pemasaran. Jakarta : Bumi Aksara. Pp101-112.

10. Ikawati, Y. 2001. Kasus Malpraktek Bisa Dikenakan PadaPerawat.Jakarta: Kompas. P 33.

11. Kotller dan Keller. 2005. Manajemen Pemasaran. Jilidi I dan II. Jakarta: PT. Indeks

12. Kotler dan Keller. 2007 Marketing Management. Global Edition. NewJersey: Pearson Education. P78.

13. Kotllerdan Keller.2009.ManagemenPemasaran.Jilid 1.Edisike13.Jakarta:Erlangga.Pp 87- 93.

14. Lovelock, Christopher H. dan Lauren K. Wright. 2007 . Manajemen Pemasaran Jasa.Cetakan II. Jakarta: PT.Indeks. Pp 18-43.

15. Notoatmodjo, S. 2007. Promosi Kesehatan dan Ilmu Perilaku. Jakarta: Rineka Cipta.Pp 202-216.

16. Notoatmodjo, S. 2005. Metodologi Penelitian Kesehatan.Jakarta:RinekaCipta.P108. Nurpeni,E. F. 2015. Rencana Pemasaran Klinik Eksekutif Rumah
SakitHermina Depok dengan Pendekatan Balanced Scorecard, Jurnal ARSI Kebijakan Kesehatan, 1(2). Pp 116- 123.0tani, K. et al. 2009 PatientSatisfaction: Focusing on Excellent,Journalof Healthcare Management, 54(2).Pp 93-103.Pasal 29 Undang-Undang No. 44 tahun 2009 tentang Rumah Sakit.

17. Prisgunanto, Ilham. 2006. Komunikasi Pemasaran: StrategidanTaktik. Bogor: Ghalia Indonesia. Pp82-87.

18. Kementrian Kesehatan Republik Indonesia. 2004. Peraturan Menteri Kesehatan Republik Indonesia Nomor 1173/MENKES/PER/2004 Tentang Rumah Sakit Gigi dan Mulut. Jakarta.

19. Sabarguna 2004. Quality Assurance pelayanan Rumah sakit,Jawa Tengah: Konsorsium RS Islam. Pp 1-22.

20. Sastroasmoro, s, Ismael, s. 2002. Dasar-dasar metodologipenelitianklinis. Jakarta:Sagung Seto.

21. Silverman, George. 2001. The Secrets of Word of Mouth Marketing. How Trigger Exponmetial Sales Through Runaway Word of Mouth. USA : Amreican Librar association. P 198.

22. Weiss, D. C. 2011. Word of Mouth, $A B A$ Journal, 97(5), pp. 53-54. Available at: http://search.ebscohost.com.ezproxy. liv.ac.uk/login.aspx?direct $=$ true $\& d b=b t$ $\& A N=61133797 \&$ site $=$ ehost-live $\&$ scope $=$ site. Diakses 28 November 2017. 